\title{
Sex and relationships guidance
}

\author{
March 2007
}

PEstyn

Arolygiaeth Ei Mawrhydi dros Addysg

a Hyfforddiant yng Nghymru

Her Majesty's Inspectorate

for Education and Training in Wales

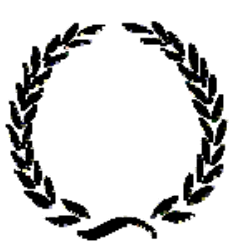

BUDDSODDWR MRFT POBE. INVESTOR IN PEOPLE 
The purpose of Estyn is to inspect quality and standards in education and training in Wales. Estyn is responsible for inspecting:

1 nursery schools and settings that are maintained by, or receive funding from, local education authorities (LEAs);

A primary schools;

A secondary schools;

i special schools;

1 pupil referral units;

A independent schools;

A further education;

ᄉ adult community-based learning;

A youth support services;

A LEAs;

teacher education and training;

^ work-based learning;

A careers companies; and

1 the education, guidance and training elements of Jobcentre plus.

Estyn also:

1 provides advice on quality and standards in education and training in Wales to the National Assembly for Wales and others; and

1 makes public good practice based on inspection evidence.

Every possible care has been taken to ensure that the information in this document is accurate at the time of going to press. Any enquiries or comments regarding this document/publication should be addressed to:

Publication Section

Estyn

Anchor Court

Keen Road

Cardiff

CF24 5JW or by email to publications@estyn.gsi.gov.uk

This and other Estyn publications are available on our website: www.estyn.gov.uk

(c) Crown Copyright 2007: This report may be re-used free of charge in any format or medium provided that it is re-used accurately and not used in a misleading context. The material must be acknowledged as Crown copyright and the title of the document/publication specified. 
$\begin{array}{ll}\text { Introduction } & 1\end{array}$

Background 2

Main findings 3

$\begin{array}{ll}\text { Recommendations } & 6\end{array}$

$\begin{array}{ll}\text { Planning and policy in schools } & 7\end{array}$

$\begin{array}{lr}\text { Curriculum organisation and teaching } & 10\end{array}$

$\begin{array}{ll}\text { Working with the wider community } & 14\end{array}$

The management and evaluation of sex and relationships education 17

$\begin{array}{ll}\text { Staff development } & 19\end{array}$

$\begin{array}{ll}\text { Confidentiality and child protection } & 20\end{array}$

$\begin{array}{ll}\text { References } & 21\end{array}$ 



\section{Introduction}

1 In its remit to Estyn for 2006-2007, the Welsh Assembly Government asked for an evaluation of the impact of Circular 11/02: Sex and Relationships Education in Schools (the Circular), in promoting effective sex and relationships education in primary, secondary, special and independent schools. This report contains that evaluation. It follows an earlier evaluation of sex and relationships education that was undertaken in 2004/05: "Sex and Relationships Education: The Implementation of the Guidance in Circular 11/02 in Schools in Wales 2004 - 2005" which can be found on the Estyn website at www.estyn.gov.uk

2 This evaluation is undertaken in the context of the Welsh Assembly Government's vision for a healthier and better educated country expressed in 'Wales: A Better Country.'

3 The evaluation reports on the impact of the guidance in the Circular. It considers the extent to which schools are now improving young people's awareness of sex and relationships as outlined in the Circular, not just by teaching them the biological facts, but also by helping them to explore feelings, relationships and moral dilemmas. It also considers how the Circular has helped teachers and other workers to address areas of uncertainty about what sex and relationships mean and how sex and relationships should be taught in schools. In this evaluation, evidence is presented on how policy and practice have been shaped since the publication of the Circular four years ago, as well as how well partnerships work to plan and deliver sex and relationships education. Good practice is identified in a number of case studies throughout the report.

This evaluation draws on:

- a detailed questionnaire response from teachers and pupils in primary, secondary, special and independent schools;

- meetings with teachers, headteachers and pupils in a range of schools across Wales;

- meetings with local authority personal and social education advisers and healthy schools co-ordinators;

- a meeting with the teacher in charge and young people from a teenage mother provision;

- discussions with local health boards;

- scrutiny of policies and schemes of work provided by schools; and

- discussions with children's and young people's groups. 


\section{Background}

5 In a recent report on "Freedom's Orphans: Raising Youth in a Changing World", the Institute for Public Policy Research notes that British teenagers are the most sexually active in Europe. The report states that twenty-five percent of young people were sexually active before the age of 16 and almost one in three 15 year olds did not use a condom during their last sexual intercourse. The report also notes that teenagers' sexual health is considerably poorer than it was a decade ago, with levels of sexually-transmitted infections rising sharply.

6 In addition to the Institute for Public Policy report, The Office for National Statistics, states on the Welsh Assembly Government web-site that, 'Within Western Europe, the UK has the highest teenage birth-rate. It is twice that of Germany, three times as high as France and six times as high as the Netherlands. Wales has consistently had a higher rate than England.' In 2004 the under-18 conception rate in Wales was 48 per 1000 for women aged 15-17 years.

These are facts that should concern all parents and carers of young people and young people themselves. The facts should also inform schools in Wales in relation to their teaching of pupils about the responsibilities and risks involved and in particular, the consideration their teaching gives to the moral and emotional aspects of sexual relationships.

As recently as 2002, the Welsh Assembly Government stated that that there was 'much uncertainty about what sex and relationships education is and how it should be taught.' To address these areas of uncertainty, the Welsh Assembly Government produced guidance on sex and relationships education in schools, Circular 11/02, in order to encourage schools to be more confident in providing holistic programmes of education.

$9 \quad$ The guidance in the Circular aimed to:

- clarify what schools are required to do by law;

- give guidance on some of the issues involved in developing a policy on teaching about sex and relationships;

- show how sex and relationships should be taught within the Personal and Social Education (PSE) framework;

- guide schools and teachers on some of the sensitive issues that schools may have to tackle when teaching about sex and relationships;

- outline some practical strategies for teaching;

- emphasise the importance of working in partnership with parents and the wider community; and

- address some of the issues concerning confidentiality. 


\section{Main findings}

10 The picture across Wales with regard to the impact of the teaching of sex and relationships education is very mixed. Since the publication of the PSE framework and Circular 11/02, there has been an increase in schools' awareness of effective practice in the teaching of sex and relationships education and the way that this should be co-ordinated and delivered. Some schools are reviewing and updating their practice but many have not done so, especially in relation to the moral and emotional aspects.

11 Overall, there are wide variations in the quality of teaching. A minority of schools teach sex and relationships education to high standards, delivering their programmes effectively and in a co-ordinated fashion, through science, PSE and religious education lessons. The remaining schools tend to rely on individual sessions that provide basic factual information but with few opportunities for learners to engage in real discussion about moral and emotional issues. In addition, few schools take pupils' views into account when planning their programmes.

12 Staff attitudes have a huge impact on the delivery of sex and relationships education in schools. Where staff are confident and well trained, sex and relationships education is delivered well. However, a majority of schools lack teachers with the appropriate knowledge, skills and confidence for good teaching and learning in this area. In some cases, too narrow a view of governors, headteachers, and sometimes parents, about what aspects of sex and relationships education pupils should be taught, impede the delivery of effective programmes, that meet the advice in the Circular. This can be through a desire on the part of this group, to protect pupils as children, rather than allow them to develop into young adults.

13 In a small minority of primary schools, as a result of good practice, pupils are well informed and are becoming more confident and aware of the issues. They display confidence in being able to deal on a theoretical basis with choices relating to sex and relationships. However, about a third of primary schools avoid teaching aspects of sex and relationships education, other than the main facts concerning puberty. Of that third, many leave the factual teaching of personal hygiene and puberty solely to the NHS Trust school nurse in one-off sessions in Year 6.

14 In the secondary phase, a number of good features can be identified:

- Where PSE is a well-planned and integrated part of the whole secondary curriculum, pupils are helped incrementally to develop confidence in thinking, listening and talking about sex and relationships. This work raises their awareness and self-esteem when dealing theoretically with difficult situations and making important choices.

- Pupils prefer lessons that are delivered by outside agencies such as sexual health professionals, or by dedicated PSE staff who are confident in their delivery. 
- In the best practice, schools having dedicated PSE lesson time, where the framework is delivered through a modular approach enhanced by the involvement of community health professionals.

17 Despite this positive picture in secondary schools, there are a number of limitations in the current practice:

- Most older pupils from Year 11 and upwards, have not benefited from a comprehensive programme of sex and relationships education and have had few lessons, if any, to raise their awareness of such issues as sexually transmitted infections, contraception and abortion.

- For many secondary schools, the practice of teaching sex and relationships education through one-off 'health days' means that not enough time is provided for pupils to discuss the moral and emotional aspects of what they are taught.

- Where PSE lessons are delivered by non-specialist teachers, staff are not confident, or are too embarrassed to teach sex and relationships education and this has an adverse effect on the quality and quantity of the lessons provided.

18 Effective teaching is also hampered in many schools because of limited time. As the PSE Framework is not statutory, lessons are sometimes not taught regularly as they are considered to be of less importance than those in National Curriculum subjects. In a few instances, pupils in key stage 4 cannot attend lessons in sex and relationships education if they choose to study certain combinations of subjects for their exams, because of timetabling constraints.

19 In many schools, the delivery and impact of PSE and, in particular sex and relationships education, are not effectively monitored.

20 There is an almost complete lack of effective links between primary and secondary schools with regard to the PSE programme and the teaching of sex and relationships education. With few exceptions, PSE co-ordinators in secondary schools do not meet with their primary colleagues to share and exchange information.

21 There is no all-Wales co-ordination to ensure consistency in planning an overall strategy for the delivery of sexual health initiatives, including the delivery of sex and relationships education in schools.

22 Although school health nurses, employed by NHS Trusts, play a vital role in the delivery of many aspects of sex and relationships education in most schools, there is no overall strategy to direct their work in relation to what is to be delivered in schools across Wales, as a matter of entitlement.

23 A few local authorities have developed strategies for the delivery of sex and relationships education, but much depends on the emphasis that individual schools place on sex and relationships education as part of their curriculum.

24 Most schools have confidentiality policies, either within their child protection or PSE policies, which make it clear that teachers cannot offer pupils unconditional confidentiality if they disclose information that is of concern. However, a few schools do not ensure that all staff are regularly updated on child protection procedures so 
that proper procedures are strictly followed, when staff become aware of child protection issues that may arise during discussions in sex and relationships education lessons. 


\section{Recommendations}

\section{The Welsh Assembly Government needs to:}

R1 consider making the PSE framework a compulsory element of the National Curriculum;

R2 strategically co-ordinate sex and relationships education entitlement in schools on an all-Wales basis; and

R3 procure exemplar materials to support the effective teaching of sex and relationships education, particularly the emotional and moral aspects;

\section{Local authorities need to:}

R4 provide further training for schools in delivering the emotional and moral aspects of sex and relationships education;

R5 facilitate a co-ordinated approach to sex and relationships education across local health boards, school health nurses, youth workers, theatre groups, young peoples' organisations and other health professionals; and

R6 take the lead in co-ordinating better links between key stage 2 and 3 for sex and relationships education;

\section{Schools need to:}

R7 take the views of pupils into account when planning or revising sex and relationships education programmes;

R8 where possible, use specialists such as PSE or religious education teachers, to deliver the moral, social and emotional aspects of sex and relationships education;

R9 ensure that sex and relationships education is taught as part of an integrated programme rather than as 'one-off' individual sessions;

R10 monitor and evaluate the impact of sex and relationships education programmes on the attitudes and behaviour of pupils;

R11 teach each aspect of sex and relationships education in line with the guidance in Circular 11/02 and raise governors' awareness of good practice; and

R12 ensure that all staff are aware of confidentiality and child protection procedures. 


\section{Planning and policy in schools}

25 Many schools are familiar with Circular 11/02 and follow the guidance when developing and writing their policies. They find that, when used in conjunction with the PSE framework, the Circular provides clear information on what should be taught at each key stage, by clarifying teachers' understanding and expectations.

26 Only a minority of schools have received training from their local authorities on how to develop policy and practice in teaching sex and relationships education based on the contents of Circular 11/02 and the PSE framework. In many cases this due to local authorities lacking funds to provide training. Those staff who have had training have found it useful in helping them to create a school policies.

27 In primary schools:

- although parents are rarely involved in policy development, in just over half of the schools, they are informed about what their children will be taught through parent governors, parent-teacher associations, the school prospectus or letters;

- where there is good practice, parents are invited to workshops to watch the videos that children will be shown and they are encouraged to discuss the content and make their views known;

- very few parents withdraw their children from lessons in sex and relationships education and most are happy for the school to take the responsibility for teaching about the onset of puberty and, in some cases, conception and birth;

- either due to the censorious attitudes of governors and headteachers or, in some cases, parents, in about a quarter of schools, teaching is solely limited to the topic of the physical changes that take place at puberty, through a desire on the part of this group to protect children and delay them developing into young adults;

- most staff use question-and-answer sessions to find what pupils already know about sex and relationships, but pupils' prior knowledge is often not taken in to account when planning follow-up sessions; and

- many plan the entire programme of sex and relationships education in advance and its delivery does not vary from year to year, despite variations in pupils' knowledge.

28 In keeping with the guidance, in secondary schools a number of key groups are involved in the shaping of policy and planning for sex and relationships education programmes. These include governors, pupils, parents and teachers.

29 In nearly all those secondary schools surveyed, governors have approved their school's policy on the teaching of sex and relationships education, but have little other involvement, athough a minority of secondary schools have a designated governor with responsibility for PSE. In the best practice, in a few schools, PSE co- 
ordinators raise governors' awareness of sex and relationships education through presentations of resource material and lesson plans which governors then discuss and comment upon.

30 In a small minority of secondary schools, where there is good practice, pupils are asked to evaluate their lessons through questionnaires or by making confidential responses and their views are taken in to account when programmes are revised. However, most secondary schools do little to involve pupils in planning sex and relationships education and pupils' prior knowledge is not considered. A minority of schools indicate that, as their school councils develop, there will be greater scope for pupils to make known their views about what is taught in PSE lessons including sex and relationships education.

31 Although parents are not involved in policy development, most schools inform parents about what will be taught in sex and relationships education through letters, the school prospectus or, in some cases, through the PTA or parent governors. Very few parents withdraw their children from lessons in sex and relationships education, being content for schools to take responsibility for this aspect of education because many parents appear to be too embarrassed to talk to their children about personal sexual matters.

32 In discussions with secondary pupils, many revealed that they do not feel able to talk to their parents about aspects of sex and relationships that are covered in school either, because pupils feel embarrassed; because they feel that parents would not be interested; or because they want to avoid confrontation on sexual matters.

33 Most faith primary schools do not teach any aspect of sex and relationships education. This is done in agreement with their partner faith secondary schools and the secondary schools ensure that puberty, conception, development and birth are taught in years 7, 8 and 9 . Faith secondary schools do not cover aspects of sex and relationships education such as contraception and abortion in ways recommended in the Circular. However, they do cover these aspects from their own faith perspective.

34 Where there is good practice in planning, teachers are developing a spiral curriculum (where each aspect of the PSE curriculum is revisited every year to build on previous learning) to teach all ten aspects of the PSE framework, including sex and relationships throughout key stage 3 and 4.

35 Most older pupils in secondary schools, from Year 11 and upwards, have not benefited from a comprehensive programme of sex and relationships education and have had few lessons, if any, to raise their awareness of such issues as sexually transmitted infections, contraception and abortion. This is due to the fact that before the publication of Circular 11/02 and the PSE framework, many schools did not teach sex and relationships education.

36 In the best practice in all schools, teaching is most effective when based on detailed lesson plans that cover all year groups taught. In such instances pupils' prior knowledge is well understood and can be built on progressively year by year. 
37 In many schools, where detailed planning does not happen, failure to take pupils' prior knowledge of sex and relationships into account can lead to the delivery of a teaching programme with significant gaps as far as the understanding of pupils is concerned.

38 There is an almost complete lack of effective links in the PSE programme and sex and relationships teaching between primary and secondary schools. With few exceptions, PSE co-ordinators in secondary schools do not meet with their primary colleagues to share and exchange information. In addition, a lack of continuity in the deployment of NHS Trust school nurses across key stage 2 and 3 means that there is little opportunity for effective links to be forged. 


\section{Curriculum organisation and teaching}

39 Since the publication of Circular 11/02 and the PSE framework, there has been a further increase in schools' awareness of effective practice in the teaching of sex and relationships education and the way that this should be co-ordinated and delivered. Some schools are reviewing and updating their practice but for many, this remains a priority.

40 Most schools teach the basic biology of sex and relationships education in line with the recommendations laid down in the Circular for the different key stages.

41 Overall, there are wide variations in the quality of teaching. A minority of schools teach sex and relationships education to high standards, delivering their programmes effectively through science, PSE and religious education lessons. The remaining schools tend to rely on one-off, individual sessions that provide basic factual information but offer few opportunities for learners to engage in appropriate discussion about moral, social and emotional aspects.

42 Staff attitudes have a huge impact on the delivery of sex and relationships education in schools. Where staff are confident and well trained, sex and relationships education is delivered well. However, in a majority of schools, a lack of specialist teaching and, in some cases, too narrow a view in relation to the Circular, about what aspects of sex and relationships education pupils should be taught, impede the delivery of effective programmes.

43 A minority of primary schools, avoid teaching aspects of sex and relationships education, other than puberty and many leave the teaching of personal hygiene and puberty solely to the NHS Trust school nurse in one-off sessions in Year 6. However, in the best practice in primary schools, where effective PSE programmes are in place, pupils are well-informed and are becoming more confident and aware of issues so that they can make relevant choices and sensible decisions when dealing with situations involving peer-pressure and bullying.

44 In secondary schools:

- where PSE is a well integrated part of the curriculum, pupils are helped to develop confidence in thinking, listening and talking about sex and relationships, helping to raise pupils' awareness and self-esteem when dealing with difficult situations and making important choices;

- pupils prefer and can identify the better quality lessons that are delivered by outside agencies or by dedicated PSE staff who are confident in their delivery;

- for many, the practice of teaching sex and relationships education through, for example, one-off 'health days' means that not enough time is provided for pupils to discuss the moral and emotional aspects of what they are taught; 
- where PSE lessons are delivered by non-specialist teachers, staff are not confident, or are too embarrassed to teach sex and relationships education and this has an adverse effect on the quality and quantity of the lessons provided; and

- effective teaching is also hampered in many schools because of limited time and, as the PSE Framework is not statutory, lessons are sometimes not taught regularly as they are considered to be of less importance than those in National Curriculum subjects;

45 In the best practice, schools have dedicated PSE lessons each week or fortnight, where the framework is delivered through a modular approach that is enhanced by outside agency involvement. In a few instances, pupils in key stage 4 cannot attend lessons in sex and relationships education if they choose to study certain combinations of subjects for their exams, because of timetabling constraints. In some schools, pupils are withdrawn from lessons in sex and relationships education or PSE in order to receive music lessons given by visiting peripatetic teachers. This arrangement signals to pupils that lessons in sex and relationships education or PSE are not important.

46 Many teachers in schools are concerned about the impact on pupils of outside pressures and the attitudes in some communities to traditional male and female stereotypes. These make it difficult for pupils to break away from stereotyping in order to make informed and independent choices about sex and relationships, even in cases where pupils have experienced good quality sex and relationships education in their schools.

47 A few secondary schools take advantage of productions by 'theatre in education' companies to teach pupils about aspects of sex and relationships such as abortion. These performances often engage pupils' interest and pose moral and emotional dilemmas for them to discuss. Pupils appreciate such opportunities and find them valuable in extending their knowledge and understanding. An example of the use of this teaching strategy is shown in case study 1 below. 


\section{Case study 1}

This case study illustrates the use of theatre in education in delivering an aspect of sex and relationships education.

In a North Wales local authority, a theatre company performed "What am I going to tell mum?" for all Year 9 pupils. The focus of the play was a teenage girl character who became pregnant but had already been left by her boyfriend. The play covers her dilemma over whether to keep the baby or have an abortion. It also shows the reaction and confusion of the ex-boyfriend when he finds out about the pregnancy.

The play stops before a decision is made to allow students to take part in a discussion with the actors about the moral issues raised in the play from the viewpoints of the different characters.

To assess the impact of the messages, students were asked to complete a questionnaire asking them to comment on several aspects of the production.

When the results were analysed, they showed that $100 \%{ }^{*}$ of the girls and $91 \%$ of the boys found the play useful in raising their awareness of the issues covered. However, only $43 \%$ of girls and $22 \%$ of boys had spoken to their parents about the performance. A significant number cited the following as reasons for this:

- a general lack of communication with parents;

- parents not being interested and;

- pupils not wanting to spark an uncomfortable lecture.

A significant number of pupils indicated that their lack of communication with their parents was due to their belief that "it was none of their business". Yet, research shows that young people are more likely to delay their first sexual encounter if they discuss sex and relationships openly with their parents.

Overall, the analysis showed that the play was a popular and relevant medium to teach this aspect of sex and relationships education. However, it also showed that such a play is only likely to have a significant impact on young people's behaviour, if it is part of a wider programme of sex and relationships education.

*Statistics taken from a local area study in a North Wales authority

48 In addition to the use of performances, as shown above, many local authorities are now deploying full or part time youth support workers in some secondary schools to provide one-to-one and small-group peer support to pupils. However, little progress has been made in developing other peer support or peer-education initiatives in many local authorities or schools to support the teaching of sex and relationships education. Peer support can be made available when pupils or young people have been trained to provide support and advice to others of a similar age. Where these schemes have been introduced, they are valued by both the pupils trained as peer supporters and by the pupils to whom the peer supporters act as informed friends. 
49 The case study below illustrates the complexities of working with peer mentoring.

\section{Case study 2}

This case study demonstrates the effective use of ICT to facilitate peer mentoring.

In one Welsh LEA, a teacher gives talks to Year 10 pupils in local schools to raise awareness of the problems of teenage sex.

As part of her talk, the teacher uses a CD of a teenage mother talking about her experience of being pregnant, giving birth and caring for the baby. The CD promotes powerfully the message that teenage mothers are ordinary young people. It shows that pregnancy is something that could happen to anyone if they choose to have unprotected sex. The CD highlights the fact that a baby does not always bring a flat and other benefits, and that, for under $16 \mathrm{~s}$, the family always has to provide all the financial support needed. It also raises awareness that teenage mothers can continue their education after having a baby but that this is not always an easy option.

It is difficult for teenage mothers to act as peer educators as many do not wish to return to school and face their peers. However, the use of the CD brings home effectively the reality of teenage pregnancy and caring for a baby.

50 Some pupils of secondary age attend youth clubs where aspects of sex and relationships education are occasionally covered by youth leaders or outside speakers. However, few, if any links have been developed between youth clubs and secondary schools to provide co-ordinated provision. 


\section{Working with the wider community}

51 Through its policy document 'Wales: A Better Country', the Welsh Assembly Government has established its vision and strategic direction to make Wales a healthier and better educated country. The document sets out the way in which the government intends to deliver this through better joint working with agencies such as local government, health services and the voluntary sector, focusing on the needs of communities and individuals.

52 Circular 11/02 emphasises that the delivery of sex and relationships education is not the sole responsibility of schools. Elements of this type of education can also be delivered by a range of people from the wider community. These people, including health professionals, social workers, youth workers, peer educators and visitors, have much to offer at all levels of planning and delivery of sex and relationships education. They bring a new perspective and offer specialist knowledge, experience and resources.

53 At local levels, planning for the improvement of health services has been integrated through the creation of local health boards to establish a multi-agency approach, including the joint provision of sexual health initiatives. However, there is no national co-ordination to ensure consistency in planning overall local authority strategies for the delivery of sexual health initiatives, including the delivery of sex and relationships education in schools, on an all-Wales basis.

54 Local health boards have established sexual health strategy groups to co-ordinate a multi-agency approach to sexual health matters. These groups do not always have a representative from the education sector other than a 'healthy schools' co-ordinator. These co-ordinators are employed, in some cases, by the local health board and in others, by the local authority. Where they are employed by the local health board, this sometimes leads to a lack of involvement of the local authority in the strategic planning of sex and relationships education in schools.

55 School health nurses, employed by NHS Trusts, play a vital role in the delivery of many aspects of sex and relationships education in most schools. However, there is no overall strategy to direct their work in relation to what is to be delivered in schools across Wales, as a matter of entitlement.

56 A few local authorities have been pro-active in co-ordinating a multi-agency approach and have provided joint training on the delivery of sex and relationships education, bringing together different agencies such as NHS Trust nurses and youth support workers. This approach is helping to ensure more consistency in sex and relationships education on a local authority wide basis.

57 However, even where there is a local authority strategy for the delivery of sex and relationships education, much depends on the emphasis that individual schools place on sex and relationships education as part of their curriculum.

58 Within this context, many primary schools are extending and consolidating their work in PSE through the 'healthy schools' initiative, but only a few have set a target for the 
teaching of sex and relationships education, as part of this scheme. The 'healthy schools' initiative is designed to help schools to educate pupils, about the benefits of all aspects of a healthy life style in line with the Welsh Assembly Government's priorities.

59 Where schools have a sex and relationships education target, the 'healthy schools' initiative can be used to give a focus to their work. The requirement for schools to maintain their on-going high level of performance to retain their 'healthy school' status helps when revisiting and reviewing their work in PSE.

60 As stated earlier, most primary schools use the services of an NHS Trust school nurse, to talk to pupils about personal hygiene and puberty and, in a very few cases, to deliver basic sex education. However, many of these sessions are not followed up by class teachers. In nearly all primary schools NHS Trust nurses and teachers do not collaborate enough, to plan the delivery of these sessions.

61 Sessions that are led by the NHS Trust school nurse in primary schools are often delivered in Year 6 . This is too late for many pupils, who have already gone through some of the changes that occur during puberty. In a few schools boys and girls were taught in separate groups to avoid pupil or adult embarrassment. This approach reinforces the idea that sex and relationships are not topics that should be discussed openly.

62 In contrast, as a follow-up to a session with the NHS Trust school nurse, good practice in schools can include opportunities presented in 'circle time' (where feelings are discussed and questions posed) and other PSE lessons, to answer pupils' questions in groups, re-inforce learning and extend their understanding of sex and relationships.

63 Around half of the secondary schools in the survey, are involved in the 'healthy schools' initiative but only a few have set targets that relate directly to the teaching of sex and relationships education.

64 In secondary schools, school-employed nurses and NHS Trust nurses are involved in the delivery of aspects of sex and relationships education such as contraception, abortion and sexually transmitted infections, but collaboration with schools to plan these sessions is rare. These sessions often consist of delivering basic factual information through PSE or 'health days' and are not followed up. They provide little opportunity for pupils to discuss and consider the moral, emotional and social implications of sex and relationships.

65 In addition, many staff and pupils report that NHS Trust school nurses often have too many demands on their time to be effective in this area. It is not uncommon for scheduled sex and relationships education sessions to be cancelled due to other pressures.

66 A minority of schools have drop-in sessions organised by the school nurse, an NHS Trust nurse or a local doctor, where pupils can receive advice and support. However, not all schools are good at providing information for pupils on where they can go for support if they have something to discuss. 
67 Around a half of secondary schools now have either a full or part-time youth support worker based in the school. These adults provide useful points of contact for advice and support, which sometimes includes discussing sex and relationships issues.

68 There is a wide variation in the nature and quality of school resources for the teaching of sex and relationships education. Although some resources are available through the 'healthy schools' initiative this is not consistent across local authorities. Several schools use resources, such as outdated videos and are therefore less effective in capturing pupils' interest and developing their knowledge.

69 Generally, across Wales, elements of good practice in working in partnership, as described in the Circular, are beginning to emerge. For example, case study 3 illustrates a curriculum activity with schools and a local health board working together.

\section{Case study 3}

This case study shows how young people's awareness can be raised of the reality of having a baby at a young age.

A local health boards uses 'virtual babies' with teenagers as part of their sex and relationships curriculum. These are programmed to cry to replicate the sound of a real baby.

The teenagers involved are taught about how to recognise and meet a baby's needs when it cries. Some students take the virtual baby home for forty eight hours and care for it as if it were real. For example, if they wish to go out, a babysitter must be found.

Most female, but not all male pupils, take the experience seriously. Having to care for the 'virtual baby' brings home to many of them for the first time, the commitment and responsibility involved in attending to a baby's needs. The experience helps young people to understand the reality of what may happen if they do not delay sexual relationships and if they have unprotected sex.

70 There is still much work to be done to improve working in partnership by all agencies in sex and relationships education in Wales. 


\section{The management and evaluation of sex and relationships education}

71 Circular 11/02 reminds schools of their statutory duty to have an up-to-date written sex education policy that describes how sex and relationships education is provided and who is responsible for providing it. The circular also highlights the need for school policies to be regularly reviewed and to outline how sex and relationships education is monitored and evaluated within the school.

72 This evaluation confirms that, nearly all schools have a designated teacher or teachers who are responsible for co-ordinating their PSE programme. Many of these co-ordinators take the lead responsibility for developing overall policy.

73 In primary schools:

- some co-ordinators, work in conjunction with headteachers to develop whole school PSE policies, that include sex and relationships education;

- only a few co-ordinators carry out informal monitoring and evaluation of the work in sex and relationships education, through staff discussion and scrutiny of pupils' work, to inform them of the success of their teaching; and

- the liaison with and co-ordination of external support is often undertaken by the headteacher, primarily with the local NHS Trust school nurse.

74 In secondary schools:

- most co-ordinators involve their colleagues and, in some cases, they work with their local authority to develop a policy for the teaching of PSE, including sex and relationships education;

- monitoring and evaluation in a few schools, are effective when all PSE lessons, throughout the school, are taught by the PSE co-ordinator who is a specialist;

- where other staff teach aspects of PSE, in a minority of schools, effective monitoring is carried out through staff discussions, scrutiny of work, pupils' lesson evaluations and occasionally, observation of lessons; and

- the liaison with and co-ordination of external services role are usually carried out by PSE co-ordinators who generally have well established links, particularly with NHS Trust nurses and they are able to organise effective, but frequently one-off sessions on aspects of sex and relationships education.

75 In many primary and secondary schools, the delivery and impact of PSE and, in particular sex and relationships education, are not effectively monitored. However, in the best practice, co-ordinators review schemes of work regularly and amend them in the light of feedback from pupils, staff and lesson observations. 
76 Many local authority PSE or 'healthy schools' co-ordinators hold regular meetings for schools' co-ordinators to share and disseminate information about aspects of PSE and this sometimes includes information and guidance on the teaching of sex and relationships education. Staff who attend these find them useful as opportunities to exchange ideas. Also, a few local authorities have provided teachers with training on the use of 'circle time' to help pupils to become better at talking and thinking about the emotional and moral aspects of sex and relationships. Similarly, the internet and news reports also provide useful sources of up-to-date information. 


\section{Staff development}

77 Although Circular 11/02 does not focus specifically on the need for staff development, this aspect emerged as an issue in the report 'Sex and Relationships Education: The implementation of the guidance in Circular 11/02 in schools in Wales in 2004 - 2005.' The 2004 - 2005 report highlighted the lack of training for teachers to refine their skills in the teaching of sex and relationships education. During the survey and visit phase of this 2006 - 2007 remit, a number of the same staff development issues emerged once again.

78 The provision of PSE training for staff is scarce for many primary and secondary schools, due to a lack of funding in local authorities. However, where local authorities do provide training for school PSE co-ordinators, this does not always cover aspects of sex and relationships education.

79 For many schools, lack of training prevents the development of their sex and relationships education programmes, especially in relation to the moral and emotional aspects. These are the aspects that many staff lack confidence in delivering. In addition, there is little training for non-specialist PSE teachers other than that provided in some schools by their own PSE co-ordinator. This however, does little to overcome staff embarrassment and lack of confidence when teaching designated aspects of sex and relationships education.

80 In an effort to overcome this lack of confidence, a minority of secondary schools are now asking staff to identify an area of PSE that they feel confident to teach. By asking staff to cover the same topics year-on-year, schools hope that this will gradually build staff confidence and have a positive impact upon the quality of the teaching.

81 Many schools feel confident to deliver sex and relationships education, only when they have the support of external agencies such as the NHS Trust school nurse, educational theatre companies or sexual health experts. However, in many cases, delivery by outside providers is not followed up in the curriculum by teachers to enable pupils to explore the moral and emotional issues that often arise. One of the main barriers to the full exploration of issues in sex and relationships education is limited curriculum time for PSE. As it is not a National Curriculum subject, schools often therefore consider it to be of less importance.

82 Where non-specialist staff are responsible for the delivery of sex and relationships education, lessons often lack purpose or impact. This is often due to the teacher's lack of confidence and embarrassment. Also, pupils who are taught by non-specialist teachers often feel uncomfortable and embarrassed to discuss issues of a sexual nature with someone who knows them in another context. In such instances, it would be preferable if they were taught by outside specialists with whom they might find it easier to discuss sensitive issues on a more impersonal level. 


\section{Confidentiality and child protection}

83 Most schools have confidentiality policies, either within their child protection or PSE policies of which staff, pupils and parents are aware. These policies make it clear that teachers cannot offer pupils unconditional confidentiality if they disclose information that is of concern. However, a minority of both primary and secondary schools do not have a specific policy on confidentiality. This means that, should a disclosure arise, the lack of a clear policy may make it difficult for staff to ensure that they act in a proper and consistent manner when dealing with issues raised by pupils.

84 In some instances, older pupils in secondary schools consider confidentiality policies a barrier to communication as it can inhibit them from speaking to members of staff to gain support and advice. Not all schools are good at providing pupils with information about who they can turn to, as an alternative source of advice, support and information about issues such as contraception.

85 Many schools receive good support from their local authorities on child protection procedures. Most local authorities provide annual update training for child protection co-ordinators. However, a few schools do not ensure that all staff are regularly updated on child protection procedures so that proper procedures are strictly followed when staff become aware of child protection issues that may arise during discussions in lessons on sex and relationships education. 


\section{References}

Sex and Relationships Education in Schools (National Assembly for Wales Circular 11/02 July 2002)

Personal and Social Education Framework Key Stages 1 to 4 in Wales (ACCAC 2000)

Sex and Relationships Education: The implementation of the guidance in Circular 11/02 in schools in Wales 2004-2005 (Estyn April 2005)

Wales: A Better Country - The Strategic Agenda of the Welsh Assembly Government (Welsh Assembly Government September 2003)

Freedom's Orphans: Raising Youth in a Changing World (Institute for Public Policy Research November 2006)

Statistics on teenage pregnancies 2004 (latest available) from the Office for National Statistics (Welsh Assembly Government website) 